\title{
Akut Osteomiyelitli Bir Yenidoğan Olgusu
}

\author{
Acute Osteomyelitis in a Newborn: A Case Report
}

\section{Emine Kavas ${ }^{1}$, Tülin Gökmen Yıldırım ${ }^{1}$, Nuray Bakal ${ }^{2}$}

Leyla Daban Kolsuz ${ }^{\text {, }}$, Selahattin Akar ${ }^{1}$, H. Fahri Ovalı ${ }^{1}$, Güner Karatekin ${ }^{1}$

1. Zeynep Kamil Kadın ve Çocuk, Eğitim ve Araştırma Hastanesi, Yenidoğan Yoğun Bakım Ünitesi, İstanbul 2. Zeynep Kamil Kadın ve Çocuk, Eğitim ve Araştırma Hastanesi, Radyoloji Kliniği, Istanbul

\section{$\ddot{O Z E T}$}

Giriş: Osteomiyelit ve septik artrit yenidoğan döneminde de görülebilen ve tedavisi zor olan enfeksiyonlardır. Yenidoğanda osteoartiküler enfeksiyonların prognozu kötü olup tanıdan şüphelenildiği anda acil tedavi gerektirir.

Olgu: Vakamız 30+3/7 haftalık, ikiz eşi olarak sezeryan ile kı bebek olarak doğdu. Doğum ă̆ırlı̆̆ 1635 gr idi. Postnatal 12. gününde bacak hareketleri sirasinda hassasiyet tespit edildi. Radyolojik incelemesi normal olarak bulundu. Postnatal 20. gününde ateş, sol üst bacakta şişlik ve hareketlerde azalma saptand. Düz grafide kemik harabiyeti tesbit edildi. Antibiyotik tedavisi başlanarak tedavisi 6 haftaya tamamland. Tedavi bitiminden sonra hastamiz taburcu edildi.

Sonuç: Bu olgumuzu, yenidoğan döneminde görülen osteoartiküler enfeksiyonların tanı ve tedavisiyle ilgili bilgi vermek için literatür eşliğinde sunduk.

Anahtar Kelimeler: osteomiyelit; yenidoğan; görüntüleme

\section{ABSTRACT}

Introduction: Osteomyelitis and septic arthritis which can be seen in the neonatal period are infections that are difficult to treat. The prognosis of the osteoarticular infections in newborns are poor and requires immediate treatment as soon as the diagnosis is suspected.

Case: Our case was a female infant and born as twins at $30+3 / 7$ weeks of gestation by cesarean section. Her birthweight was $1635 \mathrm{gr}$. In the postnatal twelfth day, tenderness was recognized during her leg movements. Radiological imaging examinations were normal. In the postnatal twentieth day fever, swelling and decreased movements of the upper part of the left leg were detected. Radiography revealed bone destruction. Antibiotic therapy was started and treatment was continued for six weeks. After the end of therapy she was discharged from the hospital.

Conclusion: We present our case to provide information about the diagnosis and treatment of the osteoarticular infections in the neonatal period according to the literature.

Keywords: osteomiyelitis; newborn; imaging

\footnotetext{
İletişim Bilgileri:

Yazışmadan Sorumlu Yazar: Emine Kavaś

Yazışma Adresi: Zeynep Kamil Kadın ve Çoc. Hast. Eğt. ve Arş. Hast., Burhaneddin Üstünel Cd. No:10, Üsküdar, İstanbul, 34668, Türkiye

E-mail: onlyemine@gmail.com

Makalenin Geliş Tarihi: 13.08.2014

Makalenin Kabul Tarihi: 27.02.2015
} 


\section{GİRİŞ}

Akut osteomiyelit, yenidoğan döneminde ilk haftada nadir rastlanır, 25-30. günlerde pik yapar ve önemli morbidite ve mortalite nedenidir $(1,2,3,4)$. Akut osteomiyelitin insidans1, hayatın ilk haftasında $\% 0,1-0,3$ olarak belirtilmiştir $(4,5)$. Yenidoğan döneminde osteomiyelit ve septik artrit invazif işlemleri takiben ya da bazı risk faktörlerine bağlı olarak gelişir. Ancak olguların çoğunda sebep tespit edilemez ve hematojen yolla geliştiği düşünülür (4). Hematojen osteomiyelit siklikla bakteriyel kaynaklı enfeksiyonlardır ancak mantarlar, virüsler veya parazitler de etken olabilir (6). Osteomiyelit, erken teşhis ve yeterli tedavi edilmediği zaman patolojik kırıklara veya büyüme bozukluklarına yol açabileceği için klinik önemi olan bir hastaliktır $(6,7)$. Osteomiyelit yenidoğan döneminde rastlanabilen bir enfeksiyon olması ve belirgin olmayan bulgularla da kendini gösterebilmesi nedeniyle, yenidoğan enfeksiyonu olarak akı1da tutulması gerektiğini düşündüğümüz için bu vakayı sunduk.

\section{OLGU}

Hastamı SAT'a göre 30+3/7 gün, sezeryan ile 1635 gr doğan, makat prezentasyon öyküsü olan kız bebek, prematürite, respiratuar distress sendromu, ikiz eşi tanıları ile yeni doğan yoğun bakım ünitesinde tedavi ve takibe alındı. Destek tedavi ve iki gün mekanik ventilatör tedavisi alan hasta, 8. gününde tam enteral beslendi. Postnatal 12. gününde anne bebeğin altını değiştirirken bebeğin sol bacağına elledikçe ağladığını belirtti. Muayenesinde sol bacakta hassasiyet dışında bir bulgu saptanmadı. İncelemelerinde sadece CRP değeri patolojik (CRP:
8,9 mg/dl) saptandı, radyografide bir özellik saptanmadı. Hastanın kültürleri alınıp sepsis, osteomiyelit ve/veya septik artrit ön tanıs1 ile antibiyotik tedavisi başland. Antibiyotiklerinin 8. gününde sol bacak proximalinde şişlik, hassasiyet, $1 \mathrm{~s} 1$ artışı ve ödem gelişti. Radyografide sol femur proksimalinde kemik harabiyeti görüldü (Resim-1). Laboratuvarda ise CRP: $1,46 \mathrm{mg} /$ dl düzeyine gerilemişti. Hastanın ilk kan kültüründe metisiline sensitif S. Aureus (MSSA) üredi, diğer kültürlerinde herhangi bir patojen saptanmadi. Tedavinin 8. gününde çekilen kalça eklemi ultrasonografisinde (USG) sol femur başı osteomiyelit ile uyumlu bulundu. Hastanın kontrastlı kalça magnetik rezonans (MR) görüntülemesinde sol femur epifizit, osteomiyelit ve septik artrit bulguları mevcuttu (Resim-2). Enfekte eklemden alınan kültürde herhangi bir patojen üremedi. Tedavide 6 hafta vankomisin, 4 hafta meropenem, 10 gün flukonazol kullanıldı, hastanın kalça eklemi immobilize edildi. Tedavilerden sonra çekilen kalça eklemi ultrasonografisinde osteomiyelit bulgusu yoktu.

\section{TARTIŞMA}

Akut hematojen osteomiyelit, yenidoğan döneminde ilk haftada nadirdir ve kolayca gözden kaçabilir $(4,8)$. Neonatal osteomiyelit insidans1 \%0,1- 0,3 arasındadır $(5,9)$. Hayatın ilk 12 ayında uzun kemiklerde metafizden köken alıp epifiz hattını vertikal olarak geçen kapillerler vardır ve böylece metafiz ile eklem boşluğu ilişki içindedir.

$\mathrm{Bu}$ nedenle yenidoğan döneminde sıklıkla osteomiyelit ile septik artrit bir aradadır (2, 4). Bizim vakamızda da, kalça MR bulguları ile osteomiyelit ve septik artritin bir arada olduğu

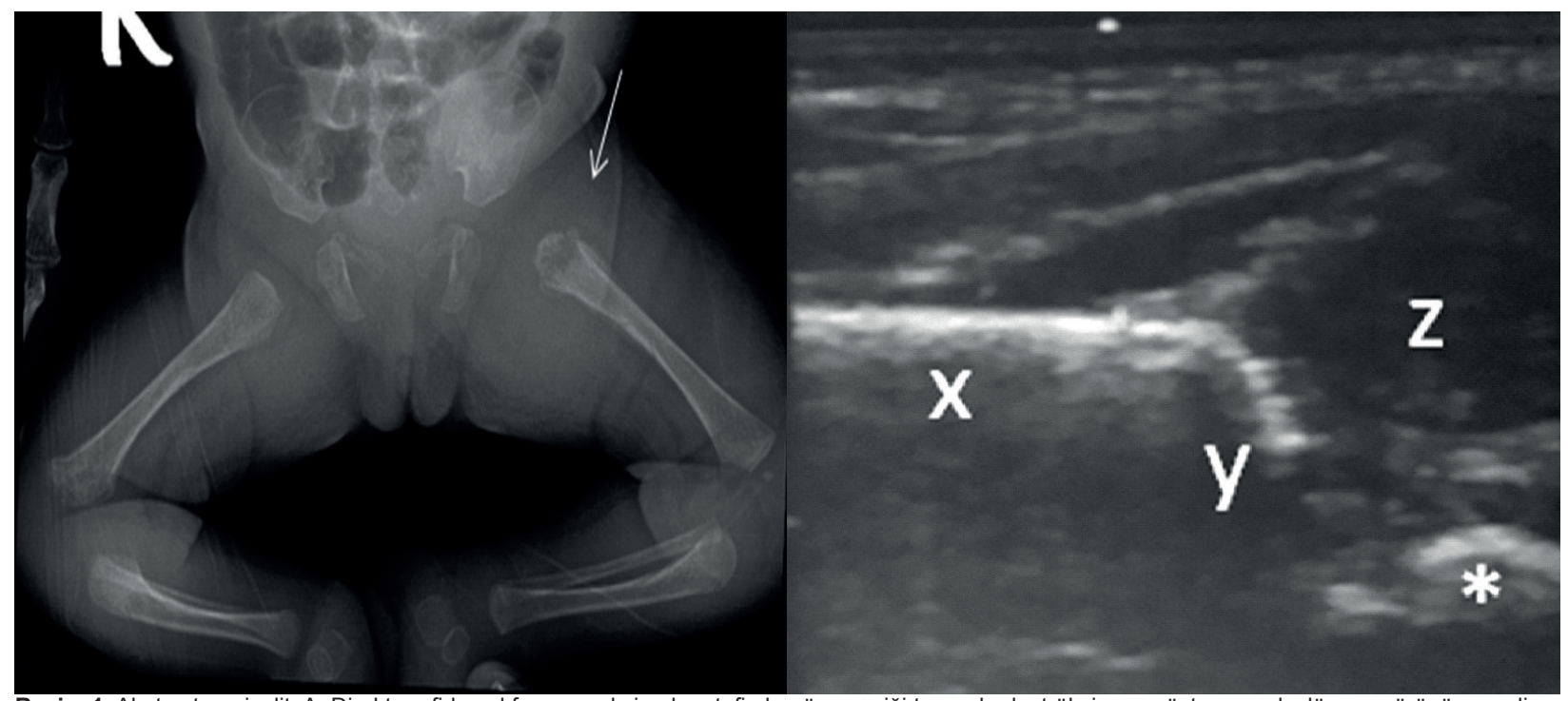

Resim 1. Akut osteomiyelit. A. Direkt grafide sol femur proksimal metafizde güve yeniği tarzında destrüksiyonu gösteren radyolüsens görünüm ve diyafize uzanım gösteren solid periosteal reaksiyon. B.Standart USG incelemede kalça ekleminde efüzyon, femur başı ile y kıkırdağı arasındaki mesafede artış, çevre yumuşak dokularda ödematöz değişikliğe bağlı ekojenite değişiklikleri. x: ileum, y: kemik asetebulum, z: femur başı, *: y kıkırdağı. 


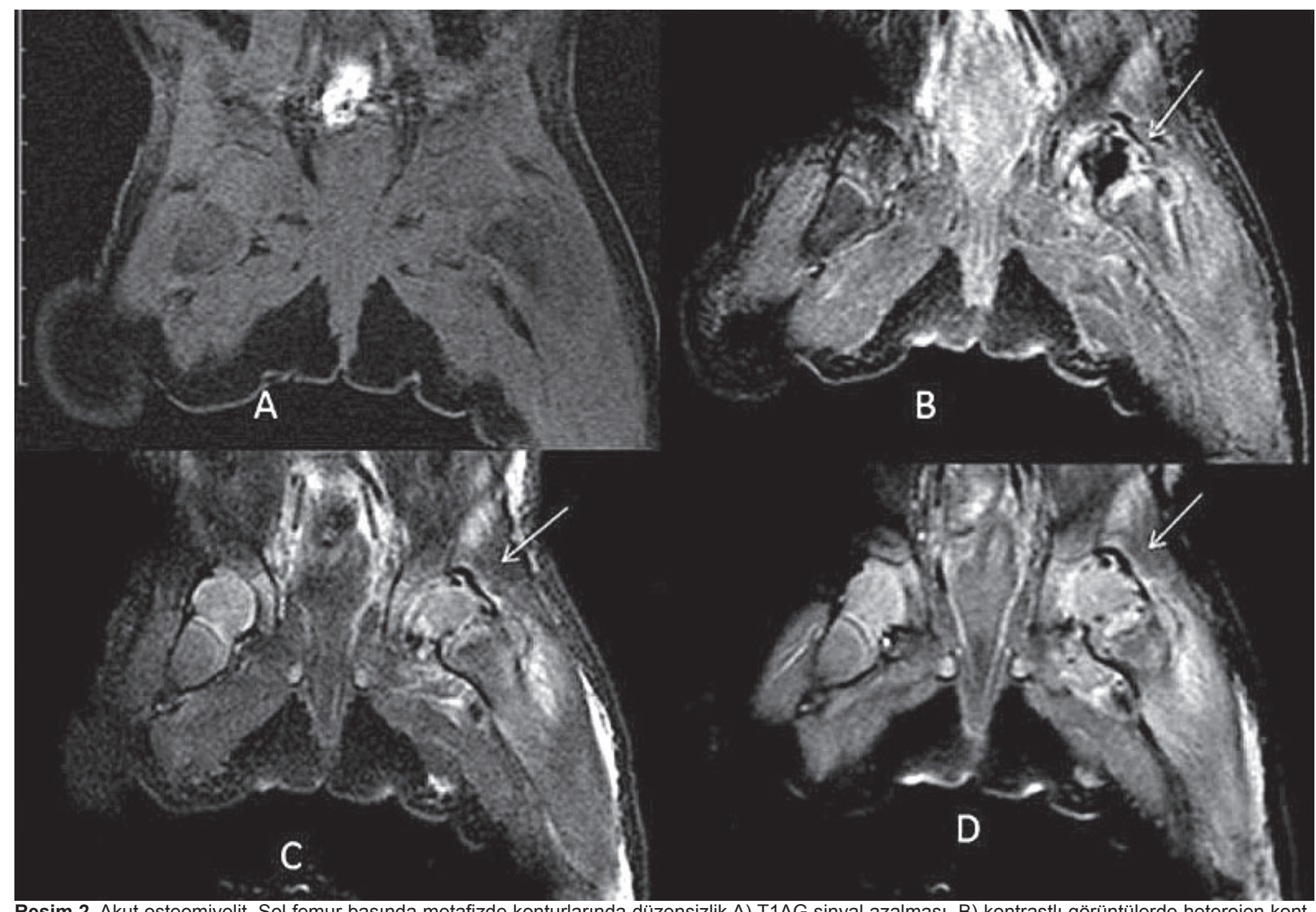

Resim 2. Akut osteomiyelit. Sol femur başında metafizde konturlarında düzensizlik A) T1AG sinyal azalması, B) kontrastlı görüntülerde heterojen kontrastlanma C. D) yağ baskılı proton ve T2A görüntülerde sinyal artışı. Eklem aralığında sıvı ve periost reaksiyonu.

saptanmıștı. Yenidoğanlarda osteomiyelit gelişmesi için belirtilen risk faktörlerinden bizim vakamizda prematürite, makat prezentasyon ve K vitamini enjeksiyonu vardı. Diğer faktörler ise korioamnionit, erken membran rüptürü, makrozomi, uzun ve zor vajinal doğum, sezeryan doğum, travma, immün yetmezlik (1), cerrahi müdahele, sepsis ya da komşu fokal enfeksiyon, kan değişimi, göbek arter- ven kateterizasyonu gibi her tür damar içi girişim (2, 9), doğumda anoksiye yol açan olaylar, erkek bebek olmak, ventilatör desteği, fetal kafa derisi monitörü, kapiller kan örneği alınması, seri lomber ponksiyonlar olarak belirtilmiştir (2). Hematojen osteomiyelit ve septik artritte en s1k etken her yaș grubunda olduğu gibi yenidoğan döneminde de S. Aureus'tur $(2,4,5,7)$. Stafilokokların yanı sıra yenidoğanda Grup B streptokoklar, gram (-) enterik basillerde etken olarak karşımıza çıkarlar (7). Stafilokoklardan da en sik metisiline rezistan S. Aureus son y1llarda rapor edilmiştir (7). Prematüre ve nazokomiyal enfeksiyonlu vakalarda etken olarak Candida türleri akılda tutulmalıdır. Bizim hastamızdan alınan ilk kan kültüründe metisiline hassas $\mathrm{S}$. Aureus izole edilmiş, eklem sıvısından herhangi bir etken elde edilememişti.

Osteomiyelit primer olarak femur ve tibiada nadiren de humerusta olur. Septik artritte \%80 gibi bir oranda kalça ekleminde ortaya çı- kar $(2,7)$. Osteomiyelitte siklıkla tek kemik tutulur (2). Bizim vakamızda da sol femur proksimalinde osteomiyelit, femur başı ekleminde septik artrit vard1.

Yenidoğan döneminde osteomiyelit ve septik artritin klinik bulgular1 nonspesifiktir ve kolayca gözden kaçabilir (7). Bizim vakamızda 12 günlükken annesi bez değişimi sırasında aşır1 ağladığını belirtmiști. İlk bulgu ödem, şişlik ya da infantın aşırı huzursuzluğudur. Diğer bulgular ateş, eritem, 1sı artış1, etkilenen ekstremitede hareket azalmasidır (pseudoparalizi) $(2,4$, 8). Pelvik osteomiyelitli çocuklarda yapılan bir çalışmada klinik bulgu olarak \%98 ağrı, \%57 ateş ve \%47 kilo artışı saptanmış (10). Kemikteki değişiklikler bizim vakamızda da olduğu gibi enfeksiyon başlangıcından en erken 7-16 gün sonra radyografide görülür, bu süreden önce radyografi ile hastalık gözden kaçabilir $(2,5,7,9)$. Diğer görüntüleme yöntemlerinden USG'nin hastalığın başlangıcında radyografiden daha yararlı olduğunu belirten bir yayında hatta deneyimli ellerde yapılan USG ile teşhisin enfeksiyon başlangıcından sonra 48 saat içinde dahi konulabilineceği belirtilmiştir $(8,11)$. USG ile periost elevasyonu erken dönemde saptanabilir, eklem sıvısı gösterilebilir, ödeme bağlı derin yumuşak dokuda heterojen eko değişiklikleri izlenebilir $(12,13)$. Yumuşak doku enfeksiyonu şüphesi ile USG çektirmediğimiz, $-86-$ 
ön tanı ile antibiyoterapiye başlanan hasta da belki o gün USG çektirsek kesin tanı koymuş olabilirdik. Bilgisayarl tomogrofi (BT) ve MR görüntülemeyi rutinde pek önermeyenler varken (7), MR görüntülemenin daha sensitif ve spesifik olduğu için yapılması gerektiğini, kemik iliği ve yumuşak doku spesifitesi nedeniyle anormalliklerini ilk 24-48 saatte saptadığını (8, $12,13)$ ve MR görüntülemenin yumuşak doku spesifitesi nedeniyle akut osteomiyelit tanısinda en duyarlı yöntem olduğunu belirtenlerde vardır $(5,9)$. MR büyüme plağına yayılımın değerlendirilmesinde, özellikle pelvik ve vertebral osteomiyelitin değerlendirilmesinde faydalıdır. Kontrast maddeli MR görüntüleme ile absenin kolayca saptanmasını sağlar $(12,13)$. Ayrıca eğer MR görüntüleme mevcut değilse BT ve kemik sintigrafisi önerilmektedir (9). Bizim vakamızda da MRI ile osteomiyelite septik artritin de eşlik ettiği gösterilmiştir.

Kan lökosit sayıs1, eritrosit sedimentasyon hızı ve akut faz reaktanları (CRP) gibi laboratuvar değerleri osteomiyelitte değişkendir ve tanıyı dişlamaz $(2,3,7)$. Vakamızda ise sadece CRP değeri yüksek bulundu. Çalışmalarda pozitif kültür sonucu \%30- \%50 iken, negatif kültür sonucu \%22- 50 arasında değiştiği belirtilmiştir. Kan ve doku kültürlerinden en s1klıkla S. Aureus (\%40) izole edilmiş $(2,3,7)$. Vakamızda da ilk kan kültüründe MSSA izole edildi, doku kültürü ve sonraki kültürlerde sonuç negatifti.

Osteomiyelitte doğru teşhis için aşağıdaki 4 kriterden en azından 2'si olmalıdır: a) pozitif kemik veya kan kültürü, b) devam eden klinik bulgular, c) pozitif görüntüleme bulguları. d) pürülan kemik içi aspirat (3). Olgumuzda bu maddelerden ilk üçü mevcuttu.

Geç teşhis edilmiş ve geç tedavi edilmiş vakalarda tutulan kemikte harabiyet, eklem deformitesi, açılanma bozuklukları, büyüme plağı etkilenirse longitudinal büyümede bozukluk, kemikte kısalık gibi uzun dönem sorunları ortaya çıkabilir $(2,7)$. Vakamızda klinik iyileşme sağlanmasına rağmen uzun dönem sonuçları için yeterli zaman geçmemiştir.

Tedavide amaç kemik ve eklemde hasar olmaması ya da minimum olması için mümkün olduğu kadar çabuk başlamaktır. Tedavi geniş spektrumlu- ampirik antibiyotik kullanımı (intravenöz, 4-6 hafta), immobilizasyon, ağrı yönetimi ve cerrahi (yumuşak dokuda sıvı birikimi varsa) drenaj ya da debridman olarak düzen- lenmelidir $(2,3,4,8)$. Vakamıza vankomisin, meropenem ve flukonazol i.v. verildi, cerrahi drenaj yapıldı, bilateral immobilize edildi.

Sonuçta osteomiyelit yenidoğanda düşünüldüğü anda tedavi gerektiren, komplikasyonları nedeniyle hızlı doğru tanıya gidilmesi gereken bir durumdur. $\mathrm{Bu}$ dönemde tutulan ekstremitede hassasiyet gibi bir bulgu göz ard1 edilmemelidir. Düz radyografi ile ilk günlerde kemik hasarı görülemeyebilir, bu nedenle doğru tanı için USG öncelikli olmak üzere ileri görüntüleme gerekliliği unutulmamalıdır.

\section{KAYNAKLAR}

1. Schiavon R, Borgo A, Micaglio A. Septic physeal separation of proximal femur in a newborn. J Orthop Traumatol 2009;10(2):105-10.

2. Overturf GD. Bacterial Infections of the Bones and Joints. In: Remington JS, Klein JO, Wilson $C B$, and Baker CJ. Infectious Diseases of the Fetus and Newborn, 7th ed. 2010. 8: 296306.

3. Cooperman DR, Thompson GH. Bone and joint infections. In: Martin RJ, Fanaroff AA, Walsh MC. Neonatal- Perinatal Medicine Diseases of the Fetus and Infant, 9th ed. 2011. 6: 1778- 1780.

4. Bünyamin B, Cevit Ö, Tanzer F, Türkay S. Yenidoğan osteomiyeliti. Türkiye Klinikleri J Med Sci 1996;16:90-92.

5. Karakaki E, Alizigakis A, Manuora A. Methicillin- Resistant Staphylococcus aureus Osteomyelitis and Septic Arthritis in Neonates: Diagnosis and Management. Jpn J Infect Dis2007;60:129-131

6. Riise QR, Kirkhus E, Handeland KS, Flato B, Reiseter T, Cvancarova M, Nakstad B, Wathne KO. Childhood osteomyelitis-incidence and differentiation from other acute onset musculoskeletal features in a population-based study. BMC Pediatr 2008;20:8-45.

7. Matic A, Gajdobranski D, Petkovic L, Velisavljev FG, Ristivojevic A. Acute osteomyelitis and septic arthritis of the shoulder in premature neonates--report of two cases. Med Pregl 2012;65(1-2):59-64.

8. Winkler S, Dai L, Hauck F, Dinger J, Pessler F. Primary osteomyelitis of the clavicle in the newborn period. Pediatr Infect Dis J 2012;31(2):211.

9. Sandal G, Uras N, Akar M, Oguz SS, Erdeve O, Dilmen U. Iliac osteomyelitis in a newborn: a case report. Journal of Pediatric Orthopaedics B 2012; 21:404-6.

10. Nar MK, Kau KE, Wu CH. Septic arthritis and acute osteomyelitis in early infancy. Clin Neonatol 1999;6:9-13.

11. Offiah AC. Acute osteomyelitis, septic arthritis and discitis: differences between neonates and older children. Eur J Radiol 2006;60:221-32

12. Ercan T. Klinik Radyoloji, 2008:710-3.

13. Zeynep Y, Ercan T. Çocuk Hastalıklarında Radyolojik Bulgular, 2002:220-222. 